This is a self-archived version of an original article. This version may differ from the original in pagination and typographic details.

Author(s): Baltazar, Margarida

Title: Musical affect regulation in adolescents : A conceptual model

Year: 2019

Version: Accepted version (Final draft)

Copyright: (C) 2019 Oxford University Press

Rights: In Copyright

Rights url: http://rightsstatements.org/page/InC/1.0/?language=en

Please cite the original version:

Baltazar, M. (2019). Musical affect regulation in adolescents : A conceptual model. In K. McFerran, P. Derrington, \& S. Saarikallio (Eds.), Handbook of Music, Adolescents, and Wellbeing (pp. 65-74). Oxford University Press. https://doi.org/10.1093/oso/9780198808992.003.0006 
(C) Margarida Baltazar 2019.

Preprint of a chapter that was originally published in "Handbook of Music and Adolescence", edited by Katrina McFerran, Phillipa Derrington, and Suvi Saarikallio, and has been reproduced by permission of Oxford University Press [https://global.oup.com/academic/product/handbook-of-music-adolescents-andwellbeing-9780198808992?cc=fi\&lang=en\&\#],

ISBN 978-0-19-880899-2

\title{
Musical affect regulation in adolescents: A conceptual model
}

\author{
Margarida Baltazar \\ University of Jyväskylä, Department of Music, Art and Culture Studies \\ margarida.baltazar@jyu.fi \\ users.jyu.fi/ anmamace
}

\begin{abstract}
Adolescents actively use music for affect regulation. In this chapter, affect is considered as a broad umbrella term containing moods, emotions, motivational impulses, and energy levels. Theoretical and empirical research has recently been unveiling the components involved in affect self-regulation, such as the psychological functions of music listening, affective goals, regulation strategies, and musical mechanisms. The study of these components and of their interactions has resulted in a better understanding of the dynamics between music engagement, wellbeing, and psychological development amongst adolescents. The purpose of this chapter is to present a conceptual model of musical affect self-regulation. The core components of the model are regulatory strategies and musical mechanisms, which interact across the dimensions of cognition, feelings, and bodily reactions.
\end{abstract}

Keywords: Adolescent, affect regulation, development, musical mechanism, music, regulation strategy, wellbeing 


\section{INTRODUCTION}

The ubiquity of music in adolescents' lives has conferred it an immense responsibility and incomparable power: the one of lifting shattered emotions, blowing the blues away, keeping it low, or changing the key. But what exactly is the role of music and how can we study it? Is there something special about music? This chapter will explore how adolescents use music to self-regulate their affect. A conceptual model of affect regulation through music will be presented, drawing support from both psychology and music research.

\section{AFFECT AND AFFECT REGULATION}

When talking about their relationship with music, adolescents often report the regulation of different affect dimensions simultaneously (e.g. "I received emotions of joy and happiness and emotional sensations. I got into a good mood and I started feeling ample [sic] and happy. I started to feel like dancing.", Saarikallio et al. 2017). Given this overlap in daily life experience, this chapter follows the suggestion of Baltazar and Saarikallio (2016) and adapts the umbrella term affect in order to include the states related to the positive/negative evaluation of external and internal stimuli. This term allows us to gather together states such as emotions, moods, motivational impulses, stress responses, and arousal (Juslin and Sloboda 2010; Scherer 2005). Affect regulation is then taken to mean all the attempts made by the young person at creating, changing, or maintaining any of these affective states. Only the regulation of one's own affective states (i.e. self-regulation) will be addressed in this chapter.

Affect is highly informative: through our feelings, we get valuable cues about what is happening around us and its meaning (Damasio 2000). However, affect cannot flow freely in a constant stream of strong emotions, moving moods, and varying levels of arousal. It requires regulation and this is a constant process where the person thrives for a better balance between personal goals, emotions, and context (Tamir and Ford 2012; Aldao and Nolen-Hoeksema 2012; Tamir 2016).

Adolescence is a special developmental stage since major changes occur at several levels - affective, biological, cognitive, social, and identity (for a review, see Gowers 2005). During these changes, emotional experiences can be more intense and unstable and social or external regulation may be decreased (Yap et al. 2007). Due to the developmental challenges faced, adolescence and early adulthood are critical points of vulnerability (Steinberg 2005). If the adolescent is lacking self-regulation skills, there is an increased risk of social difficulties, lower psychological and emo- 
tional adjustment, and internalization and externalization symptoms (Garnefski et al. 2005).

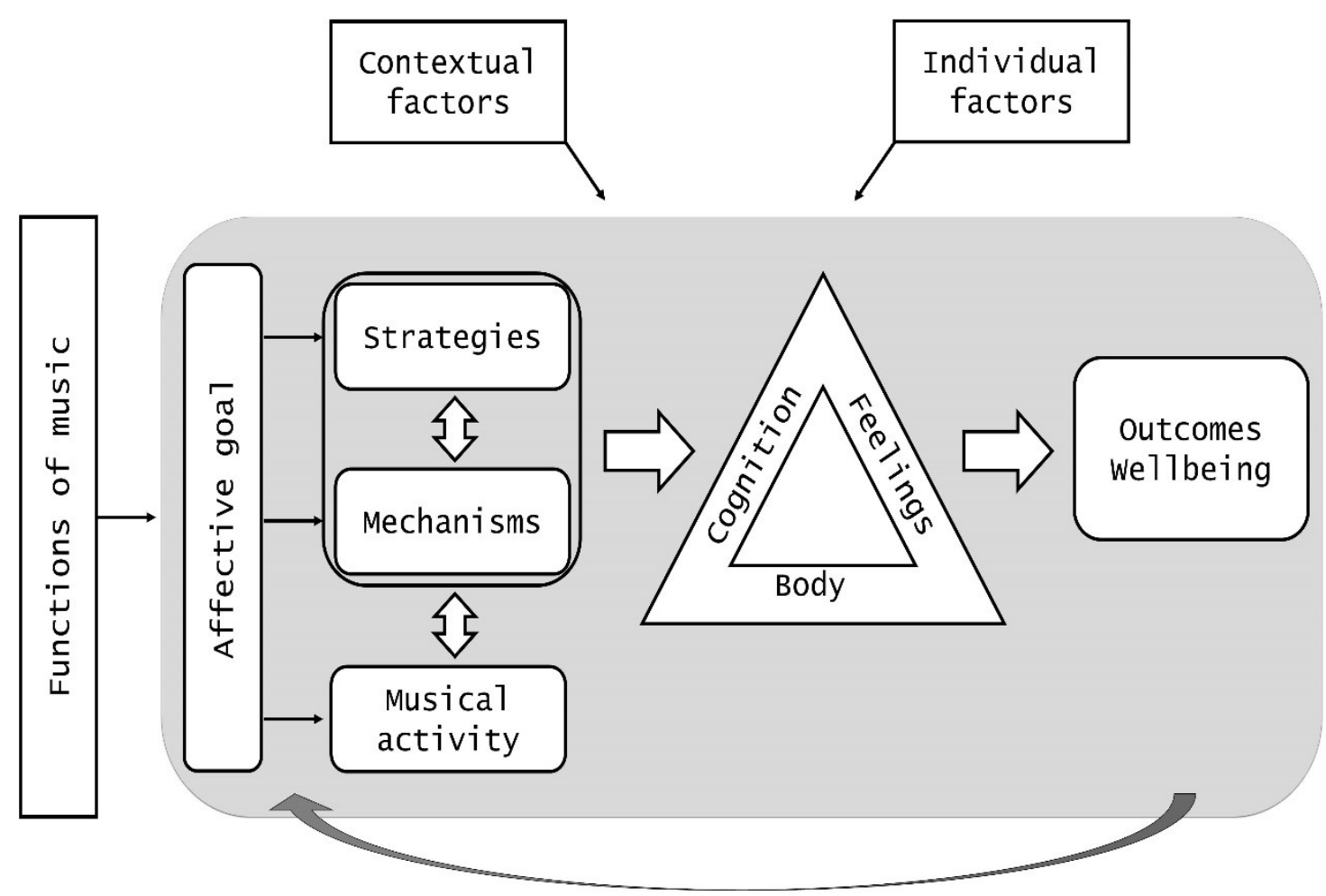

Figure 1. Integrative model of affect self-regulation through music (Baltazar and Saarikallio 2017b).

\section{MODEL OF AFFECT SELF-REGULATION THROUGH MUSIC: PUTTING THE PIECES TOGETHER}

The model depicted in Figure 1 combines several components of musical affect regulation that have been identified in recent literature (Van Goethem and Sloboda 2011; Baltazar and Saarikallio 2016, 2017a). In this model, affect regulation is one amongst 
many functions of music. The affective goals influence the choice of musical activities, regulatory strategies, and the musical mechanisms. Regulation strategies and musical mechanisms form specific associations represented in the triangle of 'cognition, feelings, body'. The process of regulation results in changes that, in the longterm, are related to the adolescents' wellbeing. Affect regulation is a continuous process, embedded in an intricate pattern of contextual and individual factors.

\section{Affective goals}

The act of regulation is considered to be driven by an affective goal, even if unconsciously (Koole and Rothermund 2011; Tamir 2016). In a healthy individual, affect regulation is flexible (Marik and Stegemann 2016) and the behavior, regulation strategies, and interaction with available resources in the environment adjust to better fit the affective goal. Similarly, in the context of music use, the affective goal guides the adolescent's decisions regarding the musical activity to engage in, the strategy to apply, and the musical mechanisms to focus on.

Adolescents might use music to achieve several affective goals, such as decreasing negative affect, increasing or maintaining positive affect, and intensifying negative states (Papinczak et al. 2015; Saarikallio and Erkkilä 2007; Tarrant et al. 2000). In psychology studies, adolescents have been found to be more prone than adults to engage in negative states or to dampen positive affect (Riediger et al. 2009) and this pattern has also been found in music listening (Cohrdes et al. 2017). Nevertheless, the goals pursued and their outcomes are heavily influenced by the adolescents' mental wellbeing and individual factors (Miranda and Gaudreau 2011; Schwartz and Fouts 2003). Of particular interest is that an increased use of music to cope with negative states has been correlated with higher levels of depression symptoms (Miranda and Claes 2009).

\section{Musical activities}

Adolescents engage in music through several types of activities - listening attentively or in the background, dancing, singing, watching music videos, composing songs, writing lyrics, amongst others (Saarikallio and Erkkilä 2007; Van Goethem 2010). One way of seeing these musical activities can be the concretization of an affective need and goal (Van Goethem and Sloboda 2011); they give the adolescent the resources for action and puts into practice the desired strategies. An ecological ap- 
proach to music suggests that musical situations convey affordances - i.e. possibilities of action belonging to an object or environment in relation to an organism (Gibson 1977). It has been argued that each musical activity has different affordances (Krueger 2014; DeNora 2000), thus supporting different regulatory actions.

Empirical results seem to support this claim. Adolescents interact with different musical activities with different purposes and strategies. In Saarikallio and Erkkilä's (2007) study, even though music listening was the most common activity for self-regulation, interesting patterns concerning other musical activities emerged. For example, singing was used for reviving, relaxing, and re-energizing through the strategy revival and forgetting about current negative mood through diversion. Writing songs, in turn, while having in common the support of relaxation and revival, was also associated with achieving new insights and understandings about the situation/feeling through mental work. These associations point to the interdependence between music, its features, and the strategic possibilities offered. For this reason, there is a bidirectional arrow between musical activity and the group strategies and mechanisms in Figure 1.

\section{Regulation strategies and musical mechanisms: At the interface be- tween the adolescent and music}

There is something fascinating in studying how the characteristics of music support its affective uses. Micro level examination may deepen our understanding of why music is so efficient and engaging. We recently conducted a study that provides useful insights into the internal organization of strategies and mechanisms and the associations between them. Data was collected through an online questionnaire from adolescents and young adults concerning their most recent episode of affect regulation through music (more details in Baltazar and Saarikallio 2017a). Participants were asked about the reason they chose music over other activities (e.g. talking to a friend, exercising). Four options were provided, each one representing the intention to focus on one of the four levels of musical affect regulation suggested by Van Goethem (2010): goals ("I wanted to be in a certain affective state"), strategies ("I wanted to use music as a 'tool' that could help me"), musical activities (tactics in Van Goethem, 2010; "I wanted to engage in music by, for example, listening, playing, or dancing to it"), and mechanisms ("I wanted to feel music's impact on me"). The answers were unequally distributed, $X^{2}(3)=36.98, p<.001$. The participants selected the options relative to strategies and mechanisms equally often, both with a proportion significantly higher than the expected mean $(\mathrm{z}=3.38, \mathrm{p}<.001)$. According to these young informants, the strategies that they can use through music and music's emotional impact on them are the main motivators behind engaging in music. Based on this, we identified regulatory strategies and musical mechanisms as the core elements for 
the adolescents' experience (Figure 1) and considered that their associations deserve further exploration.

\section{Strategies}

In a musical context, we consider strategies to be the behavioral and cognitive tools employed while performing a certain musical activity to achieve an affective goal. Regulation strategies are inherent to any human behavior and have been widely studied in psychology (for a review, see Gross 2015). However, general models from psychology do not necessarily transpose directly to the case of musical selfregulation (Randall et al. 2014). Consequently, music researchers have been devoted to the identification and analysis of the strategies involved in musical uses. Saarikallio and Erkkilä (2007) identified the following strategies used by the adolescent participants in their study: entertainment (creating a fun environment and seeking amusement), revival (relaxing, energizing, and revitalizing), strong sensation (seeking powerful feelings of pleasure, enjoyment, and excitement), diversion (detaching from undesired thoughts or feelings), discharge (expressing, releasing, or venting emotions), mental work (reflecting on and reappraising situations and reactions), and solace (seeking comforting, connecting, and meaningful experiences).

In the survey study, we presented a set of strategies based on a compilation from recent research (Baltazar and Saarikallio 2016) for the participants to identify which they had used in the self-reported musical episode. Three dimensions emerged from the analysis, representing distinct components underlying affect regulation: cognition, feelings, and bodily reactions (Figure 2). The poles of each dimension mean a higher or lower involvement of the corresponding component. 


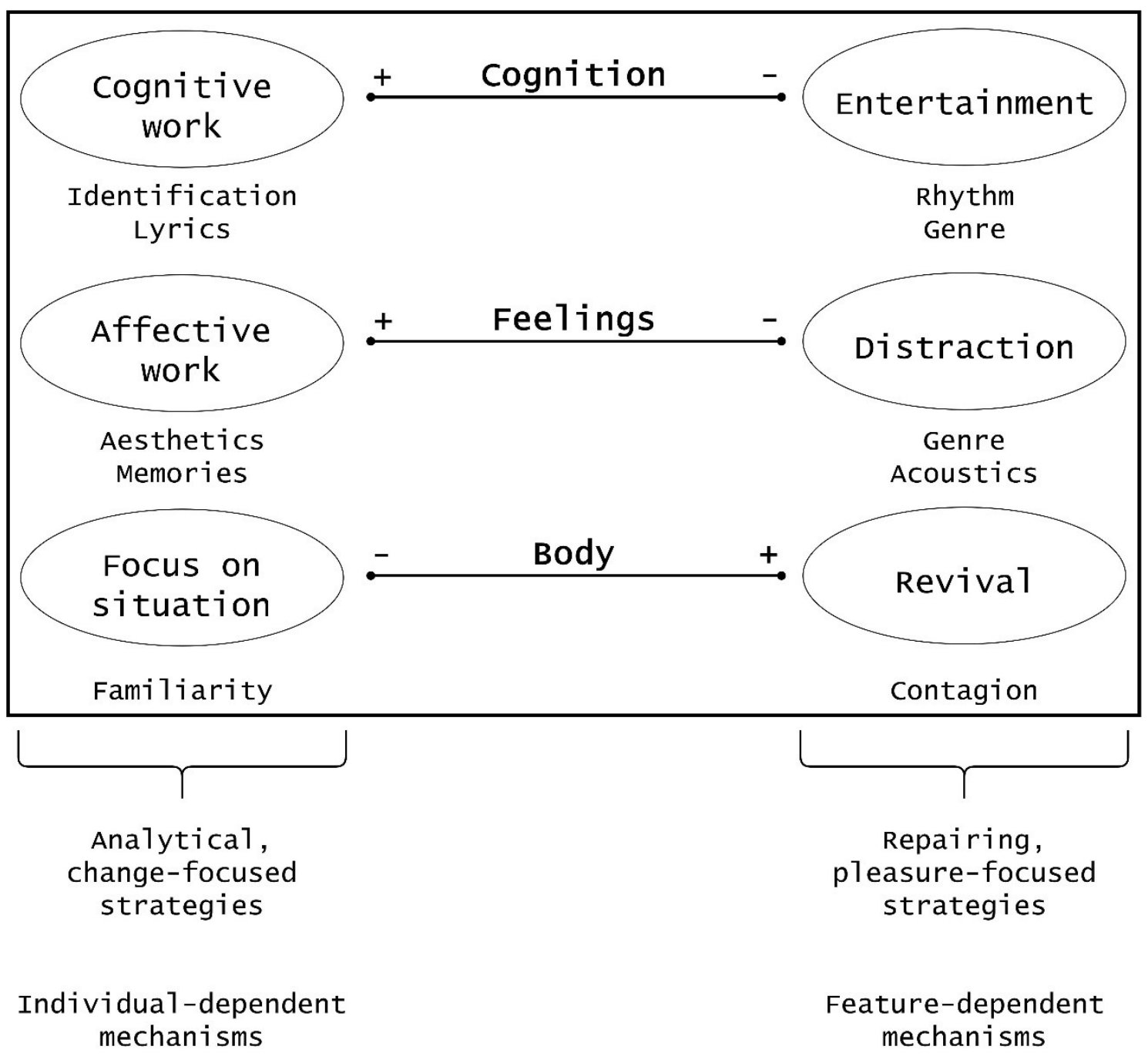

Figure 2. Associations between strategies and mechanisms across three dimensions (cognition, feelings, body).

Note. The plus/minus signs indicate the higher/lower use of that dimension's component (e.g. cognition). Adapted from Baltazar and Saarikallio (2017a) by permission of SAGE Publications.

As seen in Figure 2, the higher and lower focus on cognition, feelings, and bodily reactions while self-regulating through music creates six major groups of strategies: cognitive work (reappraisal, perspective taking, reflection, acceptance), entertainment (seek pleasurable feelings through fun), affective work (modulation of feelings, induction of strong sensations), distraction (turn the attention away from thoughts, feelings, or surroundings), revival (relaxation, energizing, increasing flow 
and endurance) and focus on situation (direct the attention to the surroundings, to the task in hand or situation).

Interestingly, these groups of strategies can be further categorized in two: analytical and change-oriented strategies versus repairing and pleasure-oriented strategies. The left side of Figure 2 is thus characterized by an active, contemplative, and cognition-loaded regulation, while the right side is characterized by a more passive, pleasure-oriented, and body-focused regulation.

\section{Musical mechanisms}

Studies on adolescents' musical regulation often report statements such as "First I am captivated by the lyrics, and then I pay attention to the melody, sonorities, and all that" or "Someone is singing, then the music's rhythm... It reaches inside me and makes me relax" (Baltazar 2009). These testimonies imply that there are qualities in the music itself or in the dyad "individual-music" that facilitate affective change. In this chapter, musical mechanisms refer to the aspects linked to music that can induce affect and support affective change.

Initial explorations of this topic have been supporting the link between musical qualities and self-regulation. Saarikallio et al. (2017) examined the interplay between strategies and mechanisms in adolescents' relaxation through music and observed that two major groups of mechanisms were used: musical (including acoustic features and emotional character of the song) and mental (including imagery and memories). Additionally, studies with adults have overall identified a large list of mechanisms that adolescents might potentially use as well (lyrics, rhythm, memories, genre, acoustic features, identification with the artist or song, aesthetics, preferences, associations, familiarity with the music, contagion, and imagery; see review in Baltazar and Saarikallio 2016).

Based on these findings, the survey study asked the participants to identify the relevant mechanisms for the reported episode. The following mechanisms contributed significantly to the model in Figure 2: identification with the artist or song, lyrics, rhythm, genre, aesthetics, memories, acoustics, contagion, and familiarity with the music. The young participants tended to get support from each mechanism in association with certain groups of strategies; these associations are illustrated in Figure 2 by placing the mechanism under the respective major strategy.

These mechanisms cover a wide range of features one can identify in relation to music. The results suggest that musical mechanisms can be grouped into individualdependent mechanisms (left side of Figure 2: identification, lyrics, aesthetics, memories, and familiarity with the music in music) and feature-dependent mechanisms 
(right side of Figure 2: contagion ${ }^{1}$, genre, acoustics, and rhythm). The featuredependent mechanisms are related to more universal characteristics of music regarding sound, style, expressed arousal and valence, while the individual-dependent mechanisms reflect a unique experience between the person and music and are linked to associations, significations, and preferences.

\section{Regulation strategies and musical mechanisms: Underlying associations}

There is an interesting pattern visible in Figure 2 that sheds some light on how musical mechanisms support the affective needs of young people. Individual-dependent mechanisms (e.g. memories) are associated with analytical and change-oriented strategies (e.g. affective work). Feature-dependent mechanisms (e.g. rhythm) are, in contrast, associated with repairing and pleasure-oriented strategies (e.g. entertainment). One might conclude that personally meaningful aspects of music have a stronger impact on affect regulation that requires larger efforts in terms of cognitive, affective, and attention processing (left side of the Figure 2), while regulation processes that disengage from the situation and internal processes (such as the ones on the right side of Figure 2) benefit from mechanisms intrinsic to music.

\section{Affective outcomes and wellbeing}

One of the driving factors for the growth of research on strategies underlying music use is their strong connection to health and affective outcomes. More and more, research has been showing that regulation strategies are a mediating variable between music uses, genre preferences, and mental health (e.g. Chin and Rickard 2014; Thomson et al. 2014). The development of adaptive and flexible regulation tools during adolescence is crucial for youth's wellbeing and mental health. Depending on the used strategies, music can be a risk or protective factor (Miranda 2013; McFerran 2016). The affective outcomes and wellbeing implications are not explored in this chapter; however, it is worth noting that, according to this model, affective musical regulation impacts-positively or negatively-the adolescent's wellbeing through the cumulative process of affective outcomes.

\footnotetext{
${ }^{1}$ Even though the term contagion might suggest an individual association, it refers to the expressed emotions of the music, which then are "mimicked" by the individual (Juslin and Västfjäll 2008). Similarly, rhythm can induce affect through entrainment. All perception is, at some level, subjective and individual and even the feature-dependent mechanisms are imbued with this subjectivity.
} 


\section{Individual and contextual factors}

Self-regulation is deeply influenced by individual and contextual factors. These two factors have reciprocal relationships, as children and adolescents are raised in a sociocultural environment that undoubtedly shapes their biopsychological development (Raver 2004).

Just as there are several types of music, there are different listeners (Ter Bogt et al. 2011). The relationship with music is rather personal, and individual traits play an important role in how adolescents use music to self-regulate. The number of hours adolescents spend listening to music, their preferred style of affect regulation, the most relevant function of music and, even, the affective outcomes of music engagement have all been traced back to individual factors such as emotional reactivity (e.g. Roberts et al. 1998), symptomatology (e.g. McFerran et al. 2015), developmental stage (e.g. Leipold and Loepthien 2015), and level of engagement with music (e.g. Ter Bogt et al. 2011).

As for contextual factors, one should bear in mind that the sociocultural context is a powerful shaping force that influences musical behavior on several levels. These influences can be observed on, for example, the adolescents' musical preferences or on their use of music to express their cultural identity (for a review, see Miranda et al. 2015). Importantly, given the culture-dependent function and meaning of emotions (Ratner 2000), adolescents need to adhere to sociocultural rules regarding their self-regulation (Eisenberg and Zhou 2000). Lastly, the specific situation surrounding the adolescent at the moment of regulation greatly dictates what are the needs, possible actions, available strategies, and desired outcomes of affect regulation (e.g. Boekaerts 2002). 


\section{CONCLUSION}

Adolescents have incorporated music in their lives and entrusted it with an important function: to help them regulate emotions, moods, and energy levels. Affect regulation is one of the many functions played by music, but it is one of the most relevant for youth's wellbeing and development.

According to the conceptual model presented in this chapter, regulatory strategies and musical mechanisms are at the core of musical regulation. Through the interaction between these two components, adolescents pursue their affective goals across the levels of cognitive, affective, and sensorial functioning. This is a dynamic process, constantly influenced by internal and external factors. The aim of this model is to provide researchers with a solid conceptual background for future studies. Prevention and intervention programs might likewise benefit from this conceptual endeavour due to the identification of key elements underlying the adolescents' musical self-regulation and contributing to their wellbeing. However, more research is needed to better understand the interconnections between each of the dimensions identified. The model can, therefore, be seen as eternally 'under construction'. 


\section{REFERENCES}

Aldao, A., and S. Nolen-Hoeksema. 2012. "The Influence of Context on the Implementation of Adaptive Emotion Regulation Strategies." Behaviour Research and Therapy 50 (7-8): pp. 493-501.

Baltazar, M. 2009. “All You Need Is Music: Caracterização Da Regulação Emocional Dos Jovens Através Da Música." Thesis. (Masters). University of Lisbon.

Baltazar, M., and S. Saarikallio. 2016. “Toward a Better Understanding and Conceptualization of Affect Self-Regulation through Music: A Critical, Integrative Literature Review." Psychology of Music 44 (6): pp. 1500-1521.

Baltazar, M., and S. Saarikallio. 2017a. "Conceptual Model of Musical Affect Regulation." Figshare. https://doi.org/10.6084/m9.figshare.5350105.v3.

Baltazar, M., and S. Saarikallio. 2017b. "Strategies and Mechanisms in Musical Affect Self-Regulation: A New Model." Musicae Scientiae. Advance online publication. doi: $10.1177 / 1029864917715061$.

Boekaerts, M. 2002. “Intensity of Emotions, Emotional Regulation, and Goal Framing: How Are They Related to Adolescents' Choice of Coping Strategies?" Anxiety, Stress \& Coping 15 (4): pp. 401-412.

Chin, T., and N. S. Rickard. 2014. "Emotion Regulation Strategy Mediates Both Positive and Negative Relationships between Music Uses and Well-Being." Psychology of Music 42 (5): pp. 692-713.

Cohrdes, C., C. Wrzus, S. Frisch, and M. Riediger. 2017. “Tune Yourself in: Valence and Arousal Preferences in Music-Listening Choices from Adolescence to Old Age." Developmental Psychology 53 (9): pp. 1777-94.

Damasio, A. 2000. "A Second Chance for Emotions." In Cognitive Neuroscience of Emotion, edited by R.D. Lane and L. Nadel, pp. 12-23. New York: Oxford University Press.

DeNora, T. 2000. Music in Everyday Life. Cambridge: Cambridge University Press.

Eisenberg, N., and Q. Zhou. 2000. "Regulation from a Developmental Perspective." Psychological Inquiry 11 (3): pp. 166-71.

Garnefski, N., V. Kraaij, and M. van Etten. 2005. "Specificity of Relations between Adolescents' Cognitive Emotion Regulation Strategies and Internalizing and Externalizing Psychopathology." Journal of Adolescence 28 (5): pp. 619-31.

Gibson, J. J. 1977. “The Theory of Affordances." In Perceiving, Acting, and Knowing: Toward an Ecological Psychology, edited by R. Shaw and J.D. Bransford, pp. 67-82. Hillsdale, NJ: Lawrence Erlbaum Associates.

Gowers, S. 2005. “Development in Adolescence." Psychiatry 4 (6): pp. 6-9.

Gross, J. J. 2015. "Emotion Regulation: Current Status and Future Prospects." Psychological Inquiry 26 (1): pp. 1-26.

Juslin, P. N., and J. A. Sloboda. 2010. "Introduction: Aims, Organization, and Terminology." In Handbook of Music and Emotion: Theory, Research, Applications, 
edited by N. Juslin, Patrik and A. Sloboda John, pp. 3-12. New York: Oxford University Press.

Juslin, P. N., and D. Västfjäll. 2008. “Emotional Responses to Music: The Need to Consider Underlying Mechanisms." The Behavioral and Brain Sciences 31 (5): pp. 559-621.

Koole, S. L., and K. Rothermund. 2011. “'I Feel Better but I Don't Know Why': The Psychology of Implicit Emotion Regulation." Cognition E Emotion 25 (3): pp. 389-99.

Krueger, J. W. 2014. "Affordances and the Musically Extended Mind." Frontiers in Psychology 4: pp. 1003-15.

Leipold, B., and T. Loepthien. 2015. "Music Reception and Emotional Regulation in Adolescence and Adulthood." Musicae Scientiae 19 (1): pp. 111-28.

Marik, M., and T. Stegemann. 2016. "Introducing a New Model of Emotion Dysregulation with Implications for Everyday Use of Music and Music Therapy." Musicae Scientiae 20 (1): pp. 53-67.

McFerran, K. S. 2016. “Contextualising the Relationship between Music, Emotions and the Well-Being of Young People: A Critical Interpretive Synthesis." Musicae Scientiae 20 (1): pp. 103-21.

McFerran, K. S., S. Garrido, L. O'Grady, D. Grocke, and S. M. Sawyer. 2015. "Examining the Relationship between Self-Reported Mood Management and Music Preferences of Australian Teenagers." Nordic Journal of Music Therapy 24 (3): pp. 187-203.

Miranda, D. 2013. "The Role of Music in Adolescent Development: Much More than the Same Old Song." International Journal of Adolescence and Youth 18 (1): pp. 522.

Miranda, D., C. Blais-Rochette, K. Vaugon, M. Osman, and M. Arias-Valenzuela. 2015. "Towards a Cultural-Developmental Psychology of Music in Adolescence." Psychology of Music 43 (2): pp. 197-218.

Miranda, D., and M. Claes. 2009. "Music Listening, Coping, Peer Affiliation and Depression in Adolescence." Psychology of Music 37 (2): pp. 215-33.

Miranda, D., and P. Gaudreau. 2011. "Music Listening and Emotional Well-Being in Adolescence: A Person- and Variable-Oriented Study." Revue Européenne de Psychologie Appliquée/European Review of Applied Psychology 61 (1): pp. 1-11.

Papinczak, Z. E., G. A. Dingle, S. R. Stoyanov, L. Hides, and O. Zelenko. 2015. "Young People's Uses of Music for Well-Being." Journal of Youth Studies 18 (9): pp. 1119-34.

Randall, W. M., N. S. Rickard, and D. A. Vella-Brodrick. 2014. “Emotional Outcomes of Regulation Strategies Used during Personal Music Listening: A Mobile Experience Sampling Study." Musicae Scientiae 18 (3): pp. 275-91.

Ratner, C. 2000. "A Cultural-Psychological Analysis of Emotions." Culture $\mathcal{E}$ Psychology 6 (1): pp. 5-39. 
Raver, C. C. 2004. "Placing Emotional Self-Regulation in Sociocultural and Socioeconomic Contexts." Child Development 75 (2): pp. 346-53.

Riediger, M., F. Schmiedek, G. G. Wagner, and U. Lindenberger. 2009. "Seeking Pleasure and Seeking Pain: Differences in Prohedonic and Contra-Hedonic Motivation from Adolescence to Old Age." Psychological Science 20 (12): pp. 1529-35.

Roberts, K. R., J. Dimsdale, P. East, and L. Friedman. 1998. “Adolescent Emotional Response to Music and Its Relationship to Risk-Taking Behaviors." Journal of Adolescent Health 23 (1): pp. 49-54.

Saarikallio, S., M. Baltazar, and D. Västfjäll. 2017. “Adolescents' Musical Relaxation: Understanding the Related Affective Processing." Nordic Journal of Music Therapy 26 (4): pp. 376-89.

Saarikallio, S., and J. Erkkilä. 2007. “The Role of Music in Adolescents' Mood Regulation." Psychology of Music 35 (1): pp. 88-109.

Saarikallio, S., C. Gold, and K. S. McFerran. 2015. "Development and Validation of the Healthy-Unhealthy Music Scale." Child and Adolescent Mental Health, no. 4: pp. 210-17.

Scherer, K. R. 2005. “What Are Emotions? And How Can They Be Measured?” Social Science Information 44 (4): pp. 695-729.

Scherer, K. R. 2009. "The Dynamic Architecture of Emotion: Evidence for the Component Process Model." Cognition E Emotion 23 (7): pp. 1307-51.

Schwartz, K. D., and G. T. Fouts. 2003. "Music Preferences, Personality Style, and Developmental Issues of Adolescents." Journal of Youth and Adolescence 32 (3): pp. 205-13.

Steinberg, L. 2005. "Cognitive and Affective Development in Adolescence." Trends in Cognitive Sciences 9 (2): pp. 69-74.

Tamir, M. 2016. “Why Do People Regulate Their Emotions? A Taxonomy of Motives in Emotion Regulation." Personality and Social Psychology Review 20 (3): pp. 199_ 222.

Tamir, M., and B. Q. Ford. 2012. "Should People Pursue Feelings That Feel Good or Feelings That Do Good? Emotional Preferences and Well-Being." Emotion 12 (5): pp. 1061-70.

Tarrant, M., A. C. North, and D. J. Hargreaves. 2000. "English and American Adolescents' Reasons for Listening to Music." Psychology of Music 28 (2): pp. 166-73.

Ter Bogt, T. F. M., J. Mulder, Q. A. W. Raaijmakers, and S. N. Gabhainn. 2011. "Moved by Music: A Typology of Music Listeners." Psychology of Music 39 (2): pp. 147-63.

Thomson, C., J. Reece, and M. Di Benedetto. 2014. “The Relationship between MusicRelated Mood Regulation and Psychopathology in Young People." Musicae Scientiae 18 (2): pp. 150-65. 
Van Goethem, A. 2010. "Affect Regulation in Everyday Life: Strategies, Tactics and the Role of Music." Thesis. (PhD). UK: Keele University.

Van Goethem, A., and J. A. Sloboda. 2011. "The Functions of Music for Affect Regulation." Musicae Scientiae 15 (2): pp. 208-28.

Yap, M. B., N. Allen, and L. Sheeber. 2007. "Using an Emotion Regulation Framework to Understand the Role of Temperament and Family Processes in Risk for Adolescent Depressive Disorders." Clinical Child and Family Psychology Review 10 (2): pp. 180-96. 